\title{
Adipocytes from Munc18c-null mice show increased sensitivity to insulin- stimulated GLUT4 externalization
}

\author{
Hajime Kanda, ${ }^{1}$ Yoshikazu Tamori, ${ }^{1}$ Hiroaki Shinoda, ${ }^{1}$ Mari Yoshikawa, ${ }^{1}$ Motoyoshi Sakaue, ${ }^{1}$ \\ Jun Udagawa, ${ }^{2}$ Hiroki Otani, ${ }^{2}$ Fumi Tashiro, ${ }^{3}$ Jun-ichi Miyazaki, ${ }^{3}$ and Masato Kasuga ${ }^{1}$
}

1Department of Clinical Molecular Medicine, Kobe University Graduate School of Medicine, Kobe, Japan. 2Department of Developmental Biology, Faculty of Medicine, Shimane University, Izumo, Japan. ${ }^{3}$ Division of Stem Cell Regulation Research, Osaka University Graduate School of Medicine, Osaka, Japan.

\begin{abstract}
Insulin-stimulated glucose uptake in adipocytes is mediated by translocation of vesicles containing the glucose transporter GLUT4 from intracellular storage sites to the cell periphery and the subsequent fusion of these vesicles with the plasma membrane, resulting in the externalization of GLUT4. Fusion of the GLUT4-containing vesicles with the plasma membrane is mediated by a soluble $N$-ethylmaleimide-sensitive factor attachment protein receptor (SNARE) complex consisting of vesicle-associated membrane protein 2 (VAMP2), 23-kDa synaptosomal-associated protein (SNAP23), and syntaxin4. We have now generated mouse embryos deficient in the syntaxin 4 binding protein Munc18c and show that the insulininduced appearance of GLUT4 at the cell surface is enhanced in adipocytes derived from these Munc18c $\mathrm{c}^{-/-}$ mice compared with that in Munc18 $\mathrm{c}^{+/+}$cells. Wortmannin, an inhibitor of PI3K, inhibited insulin-stimulated GLUT4 externalization, without affecting GLUT4 translocation to the cell periphery, in Munc18c $\mathrm{c}^{+/+}$ adipocytes, but it did not affect GLUT4 externalization in Munc18 $\mathrm{c}^{-/-}$cells. Phosphatidylinositol 3-phosphate, which induced GLUT4 translocation to the cell periphery without externalization in Munc18 $\mathrm{c}^{+/+}$ cells, elicited GLUT4 externalization in Munc18 $\mathrm{c}^{-/-}$cells. These findings demonstrate that Munc18c inhibits insulin-stimulated externalization of GLUT4 in a wortmannin-sensitive manner, and they suggest that disruption of the interaction between syntaxin 4 and Munc18c in adipocytes might result in enhancement of insulin-stimulated GLUT4 externalization.
\end{abstract}

\section{Introduction}

The plasma concentration of glucose is strictly controlled in normal individuals through the regulation of the balance among glucose absorption from the intestine, production by the liver, and uptake by peripheral tissues. Most postprandial glucose uptake in peripheral tissues occurs in skeletal muscle and adipose tissue, in both of which the insulin-regulated glucose transporter GLUT4 is predominantly expressed. Insulin-dependent glucose uptake in these tissues results from the translocation of GLUT4-containing vesicles from intracellular storage sites to the cell periphery and the subsequent fusion of these vesicles with the plasma membrane, resulting in the externalization of GLUT4 $(1,2)$. The fusion of GLUT4 vesicles with the plasma membrane is mediated by a soluble $\mathrm{N}$-ethylmaleimide-sensitive factor attachment protein receptor (SNARE) complex that consists of vesicle-associated membrane protein 2 (VAMP2), 23-kDa synaptosomal-associated protein (SNAP23), and syntaxin4 (3-9). The activation of a PI3K-dependent signaling pathway is necessary for insulin-induced exocytosis of GLUT4-containing vesicles (10). However, the mechanism by which insulin regulates formation of the SNARE protein complex has remained unknown.

Nonstandard abbreviations used: $\mathrm{dpc}$, days postcoitum; IRES, internal ribosome entry site; IRS, insulin receptor substrate; MEF, mesenchymal embryonic fibroblast; PI3P, phosphatidylinositol 3-phosphate; SNAP23, 23-kDa synaptosomal-associated protein; SNARE, soluble $\mathrm{N}$-ethylmaleimide-sensitive factor attachment protein receptor; VAMP2, vesicle-associated membrane protein 2.

Conflict of interest: The authors have declared that no conflict of interest exists.

Citation for this article: J. Clin. Invest. 115:291-301 (2005)

doi:10.1172/JCI200522681
The syntaxin-binding protein Munc18 is a mammalian homolog of 2 regulators of vesicle trafficking in Saccharomyces cerevisiae (Sec1) and Caenorbabditis elegans (UNC-18). Munc18-1 (also known as Munc18a), 1 of the 3 identified isoforms of Munc18, is expressed predominantly in neuronal tissues (11-13) and has been shown to play an essential role in neurotransmitter release in a study of Munc18-1-knockout mice (14). Munc18b and Munc18c are expressed ubiquitously, but only the latter isoform is implicated in the regulation of GLUT4 translocation in adipocytes $(5,6$, $7,15)$. The precise function of Munc18c in insulin-stimulated exocytosis of GLUT4-containing vesicles has been unclear, however. Two studies have suggested that Munc18c plays an inhibitory role in the insulin-stimulated translocation of GLUT4 to the plasma membrane in adipocytes $(6,7)$, whereas another has suggested that Munc18c is required for the insulin-induced fusion of GLUT4 vesicles with the plasma membrane in these cells (15).

To clarify the physiological function of Munc18c in insulinstimulated GLUT4 exocytosis, we have generated Munc18cknockout mice by homologous recombination. Given that the homozygous mutant animals died in utero or soon after birth, we generated adipocytes that lack Munc18c by inducing adipogenesis in mesenchymal embryonic fibroblasts (MEFs) derived from the Munc $18 \mathrm{c}^{-/-}$mouse embryos and examined the effects of insulin on GLUT4 localization in these cells.

\section{Results}

Munc18c/- mice die either in utero or as neonates. We generated mice in which the Munc18c gene was disrupted as a result of homologous recombination. A targeting vector was designed to replace the exon 


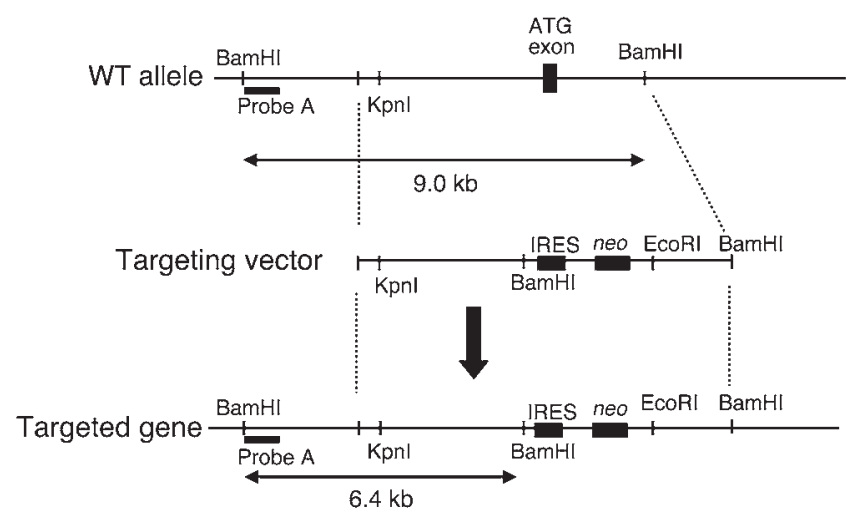

Figure 1

Targeted deletion of Munc18c in mice. The wild-type Munc18c allele, the targeting vector, and the targeted allele after homologous recombination are shown. Probe A is a DNA fragment used for Southern blot analysis of BamHI-digested genomic DNA from ES cells; the wild-type and mutant alleles give rise to 9.0 - and $6.4-\mathrm{kb}$ hybridizing fragments, respectively.

that includes the ATG initiation codon with the neomycin resistance gene and an internal ribosome entry site (IRES) sequence (Figure 1). Screening of neomycin-resistant ES cells by Southern blot analysis identified 4 cell clones that had undergone appropriate recombination. One line of chimeric mice was obtained from these recombinant ES cells. We generated Munc18 $\mathrm{c}^{+/-}$mice by mating the chimeric animals with C57BL/6J mice. All Munc18 $\mathrm{c}^{-/-}$ mice died either in utero or within 6 hours after birth. At 13.5 days postcoitum (dpc), the Munc18c $\mathrm{c}^{-/}$embryos were $17 \%$ shorter than were wild-type embryos (mean body lengths, $8.9 \mathrm{~mm}$ and 10.8 $\mathrm{mm}$, respectively) (Figure 2A). Live newborn Munc $18 \mathrm{c}^{-/-}$mice were also $30 \%$ shorter than Munc18 $\mathrm{c}^{+/+}$animals (mean body lengths, $19.1 \mathrm{~mm}$ and $27.3 \mathrm{~mm}$, respectively) (Figure 2B). The intermediate zone of the cerebral cortex of newborn Munc18 $\mathrm{c}^{-/-}$mice con- tained poorly formed neural fibers and a greater number of cellular components compared with Munc18c $\mathrm{c}^{+/+}$animals (Figure 2C). Furthermore, the border between the subventricular and intermediate zones was indistinct in Munc18 $\mathrm{c}^{-/-}$mice. These results thus suggest that Munc18c is essential for normal brain development. The precise mechanisms by which Munc18c deficiency gives rise to intrauterine growth retardation and embryonic or neonatal death remain to be defined.

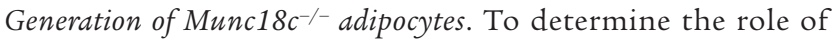
Munc18c in insulin-stimulated GLUT4 exocytosis, we generated adipocytes that lack this protein by inducing the differentiation of MEFs isolated from Munc18 $\mathrm{c}^{-/-}$animals at $13.5 \mathrm{dpc}$. We first examined adipogenesis in the Munc18 $\mathrm{c}^{-/-}$cells by staining with oil red $\mathrm{O}$, which detects triglycerides. The proportion of MEFs that differentiated into adipocytes was similar in populations

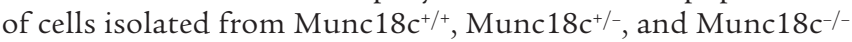
embryos (Figure 3A). Furthermore, the triglyceride content of the differentiated cells did not differ significantly among the 3 genotypes (Figure 3B), which suggests that Munc18c does not affect adipogenesis in vitro.

SNARE protein expression in Munc18c-/- adipocytes. We next examined the expression of SNARE proteins in Munc $18 \mathrm{c}^{-/-}$adipocytes. Northern blot analysis revealed that the amounts of syntaxin4, SNAP23, and VAMP2 mRNAs did not differ among Munc18 $\mathrm{c}^{+/+}$, Munc18 $\mathrm{c}^{+/-}$, and Munc18 $\mathrm{c}^{-/-}$adipocytes (Figure 4A). The abundance of another isoform of Munc18, Munc18b, also did not differ among these adipocytes (Figure 4A). Immunoblot analysis, however, showed that the amount of syntaxin4, which forms a complex with Munc18c in adipocytes (6), was markedly reduced in Munc18 $\mathrm{c}^{-/-}$ adipocytes and slightly reduced in Munc18 $\mathrm{c}^{+} /-$cells compared with that in wild-type cells (Figure 4B). In contrast, the abundance of SNAP23 or VAMP2 did not differ among adipocytes of the 3 genotypes. Furthermore, the expression of syntaxin2, which does not bind to Munc18c in adipocytes (6), was not affected by Munc18c deficiency. These results suggest that Munc18c might stabilize syntaxin 4 by forming a complex with it in adipocytes.

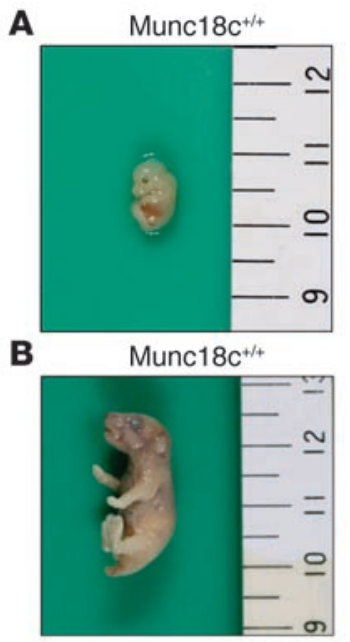

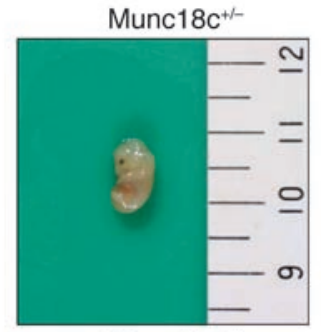

Munc18 $\mathrm{c}^{+/-}$

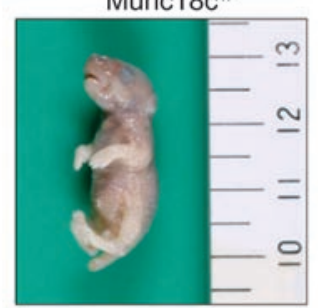

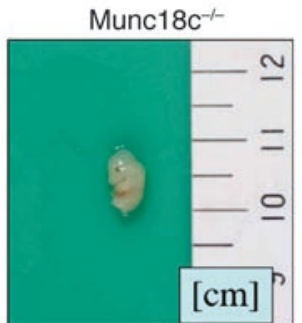

Munc18 $18 \mathrm{c}^{-1-}$

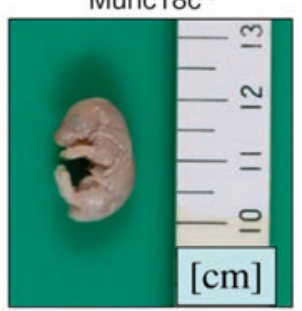

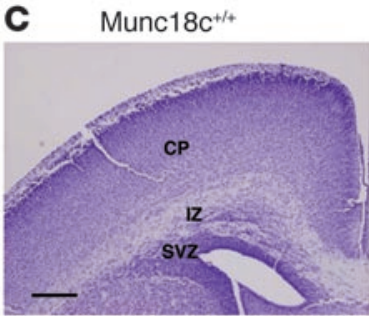

Munc18c $\mathrm{c}^{-/-}$

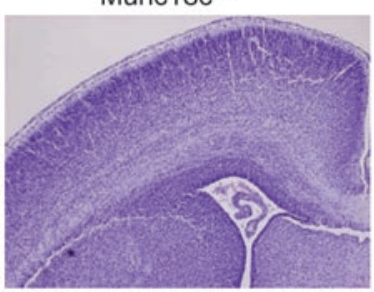

\section{Figure 2}

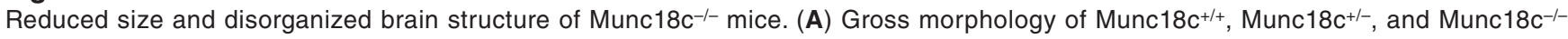
embryos at 13.5 dpc. (B) Gross morphology of Munc18c $\mathrm{c}^{+/+}$, Munc18c $\mathrm{c}^{+-}$, and Munc $18 \mathrm{c}^{-/-}$newborn mice. (C) Coronal sections of the brain of newborn Munc $18 \mathrm{c}^{+/+}$and Munc18 $\mathrm{c}^{-/-}$mice. The sections were stained with Nissl solution. CP, cortical plate; IZ, intermediate zone; SVZ, subventricular zone. Scale bar: $200 \mu \mathrm{m}$. 
A

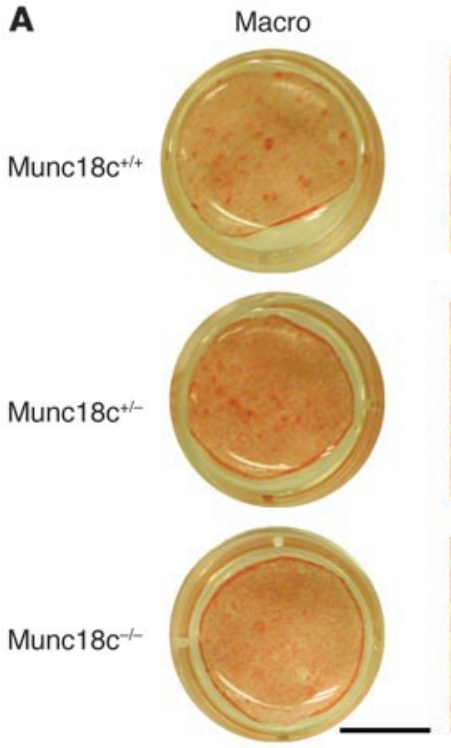

B
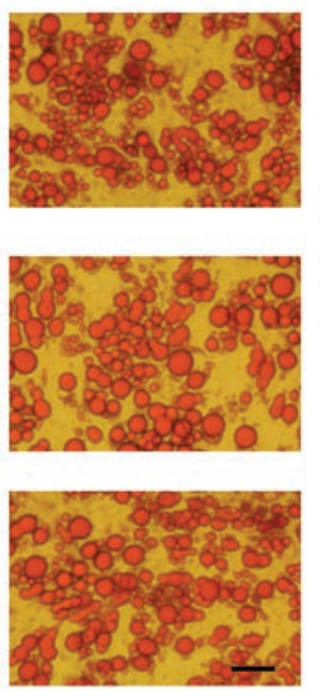

\section{Figure 3}

Lack of effect of Munc18c on adipocyte differentiation in MEFs. (A) Adipocyte differentiation was induced in

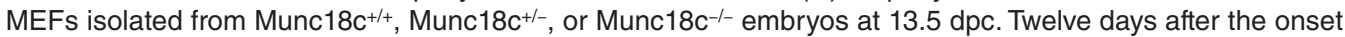
of induction, adipocytes were fixed, stained with oil red $\mathrm{O}$, and examined both macroscopically (Macro) and microscopically (Micro). Scale bars: $10 \mathrm{~mm}$ (left panels) and $50 \mu \mathrm{m}$ (right panels). (B) Intracellular triglyceride (TG) content was quantified as described in Methods. The amount of TG content in adipocytes of each genotype was normalized to protein concentration. Data are mean \pm SE of values from 4 independent experiments and are expressed relative to the value for Munc $18 \mathrm{c}^{+/+}$.

The binding of Munc18c to syntaxin 4 inhibits the association of the latter protein with SNAP23 or VAMP2 $(4,5,7)$, which suggests that, in the absence of Munc18c, syntaxin 4 might be free to form a SNARE complex with SNAP23 and VAMP2. Moreover, the ratio of the amounts of syntaxin 4 and Munc18c, rather than the absolute abundance of these proteins, has been shown to affect insulin-stimulated glucose uptake in skeletal muscle and adipose tissue (16). We therefore next examined the amount of Munc18cfree syntaxin 4 in Munc18 $\mathrm{c}^{+/+}$, Munc18 $\mathrm{c}^{+/-}$, and Munc18 $\mathrm{c}^{-/-}$ adipocytes with the use of an $\mathrm{mAb}(\mathrm{A} 6 \mathrm{C})$ that immunoprecipitates only syntaxin 4 molecules that are not associated with Munc18c (Figure 5A). Whereas the total amount of syntaxin 4 was significantly reduced in Munc18 $\mathrm{c}^{-/-}$adipocytes (Figure 5B), the amount of syntaxin 4 immunoprecipitated by the $\mathrm{A} 6 \mathrm{C}$ antibody was increased by approximately 2.5 -fold in these cells compared with that in Munc18 $\mathrm{c}^{+/+}$or Munc18 $\mathrm{c}^{+/-}$adipocytes (Figure 5C). These results thus indicate that the amount of Munc18c-free syntaxin 4 is increased in Munc18 $\mathrm{c}^{-/-}$adipocytes even though the total amount of syntaxin 4 is reduced.

\section{Figure 4}

Reduced abundance of syntaxin4 in Munc18c-/- adipocytes. (A) Northern blot analysis of mRNAs for SNARE proteins. Total RNA extracted

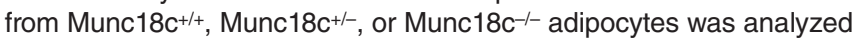
for hybridization with probes specific for Munc18c, syntaxin4, SNAP23, VAMP2, or Munc18b mRNAs. The region of the ethidium bromidestained gel containing $28 \mathrm{~S}$ ribosomal RNA (rRNA) is also shown. (B) Immunoblot analysis of SNARE proteins. Lysates prepared from adipocytes of each genotype were subjected to immunoblot analysis with antibodies specific for the indicated proteins.

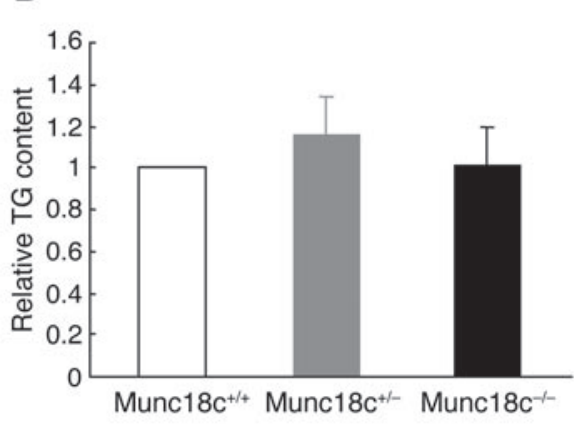

Munc18c $\mathrm{c}^{+/+}$Munc18 $\mathrm{c}^{+/-}$Munc18 $\mathrm{c}^{-1-}$
Deficiency of Munc18c does not affect proximal insulin signaling. We examined whether proximal insulin signaling implicated in GLUT4 exocytosis in adipocytes was affected by the lack of Munc18c. No marked difference in the extent either of tyrosine phosphorylation of the insulin receptor or insulin receptor substrate (IRS) or of serine phosphorylation of the downstream kinase Akt induced by stimulation with insulin (1 or $100 \mathrm{nM}$ ) for 5 minutes was apparent among Munc18 $\mathrm{c}^{+/+}$, Munc18c $\mathrm{c}^{+/}$, and Munc18 $\mathrm{c}^{-/-}$ adipocytes (Figure 6). The absence of Munc18c thus does not affect the activity of major molecules that mediate proximal insulin signaling.

Enhancement of insulinstimulated GLUT4 externalization in Munc18c-/adipocytes. We next determined the subcellular localization of endogenous GLUT4 in Munc18 $\mathrm{c}^{-/-}$adipocytes. Subcellular fractionation and subsequent immunoblot analysis with antibodies to GLUT4 revealed that, upon stimulation with $100 \mathrm{nM}$ insulin for 20 minutes, GLUT4 translocated from intracellular storage sites to the plas-

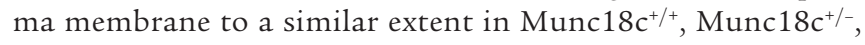
and Munc18 $18 \mathrm{c}^{-/}$adipocytes (Figure 7, A and B), which suggests that Munc18c does not contribute to this process. To distinguish between the movement of GLUT4 vesicles to the cell periphery and the subsequent fusion of the vesicles with the plasma membrane and GLUT4 externalization, we studied adipocytes that had been infected with a retroviral vector encoding a form of GLUT4

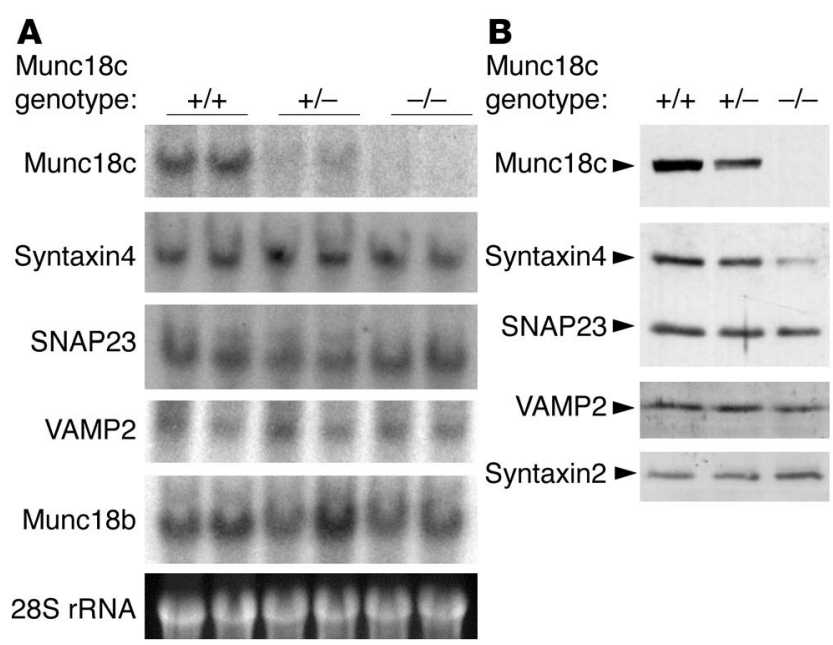


A

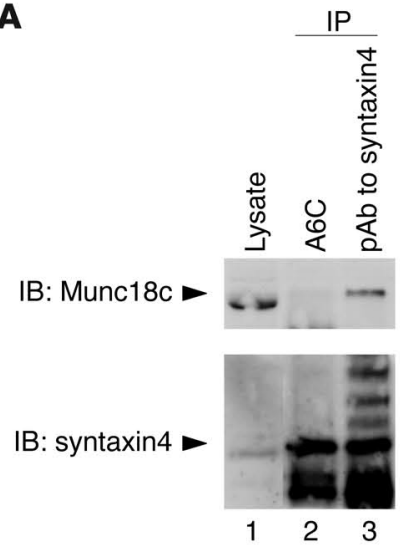

B
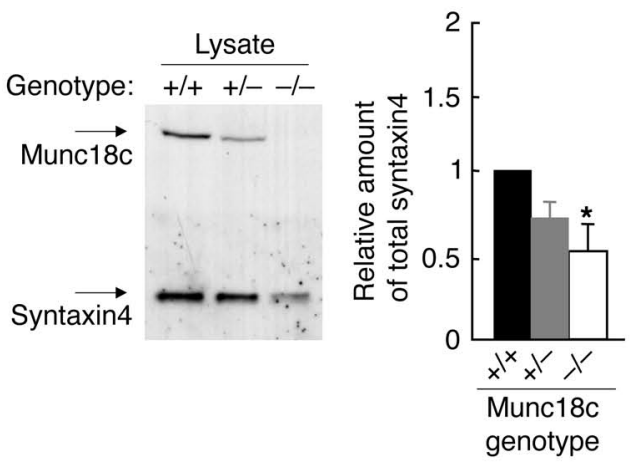

C

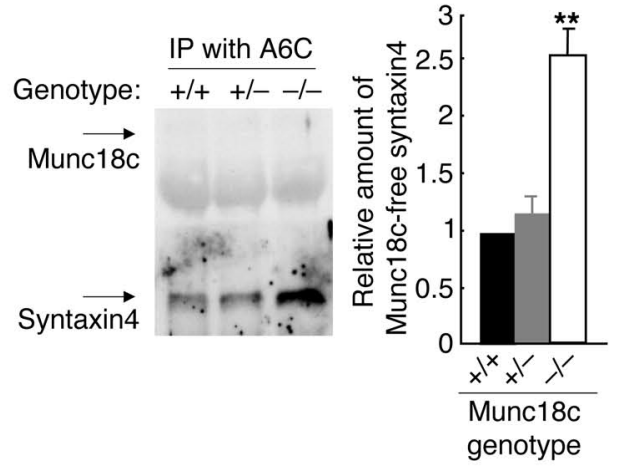

Figure 5

Increased amount of Munc18c-free syntaxin4 in Munc18c-/- adipocytes. (A) Immunoprecipitation of Munc18c-free syntaxin4 by the mAb A6C. COS-7 cells were transfected with expression plasmids for full-length rat synatxin4 and mouse Munc18c, after which cell lysates were subjected to immunoprecipitation with the A6C antibody (lane 2) or with polyclonal antibodies (pAb) to syntaxin4 (lane 3). The resulting precipitates, as well as the original cell lysate (lane 1), were subjected to immunoblot analysis with polyclonal antibodies to syntaxin4 (lower panel) and with polyclonal antibodies to Munc18c (upper panel). Munc18c was not associated with syntaxin4 immunoprecipitated by A6C (lane 2) but was present in the immunoprecipitate prepared with the polyclonal antibodies to syntaxin4 (lane 3). (B and C) Quantitation of Munc18c-free syntaxin4 in adipocytes.

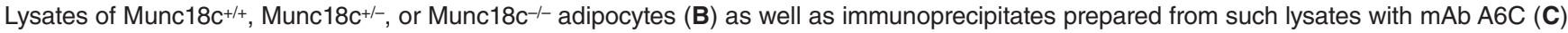
were subjected to immunoblot analysis with polyclonal antibodies to syntaxin 4 or to Munc18c. The bands corresponding to total syntaxin4 (B) and to Munc18c-free syntaxin4 (C) were quantitated and expressed relative to the corresponding values for Munc18c ${ }^{+/+}$cells. Data are mean \pm SE of values from 4 independent experiments. ${ }^{*} P<0.05,{ }^{* \star} P<0.001$ versus Munc18c ${ }^{+/+}$cells (Student's $t$ test).

(GLUT4-myc7-GFP) that contains 7 Myc epitope tags in its first extracellular loop and is fused with GFP at its intracellular COOH-terminus (17). The insulin-induced movement of GLUT4 to the plasma membrane was monitored by measurement of GFP fluorescence at the cell periphery, and GLUT4 externalization was monitored by measurement of cell surface labeling with antibodies to the Myc tag. To exclude the possibility that GFP protein is not always fluorescent in adipocytes, we confirmed that insulin-induced localization of GLUT4 in Munc $18 \mathrm{c}^{+/+}$adipocytes was the same whether determined by immunodetection with anti-GFP antibody or GFP fluorescence (data not shown). The extent of GLUT4 movement to the cell periphery was similar upon 20-minute stimulation of cells with either 1 or $100 \mathrm{nM}$ insulin, and similar results were obtained with adipocytes of each of the 3 genotypes (Figure 8, A and B). Munc18c thus does not appear to affect the insulin-stimulated translocation of GLUT4 to the plasma membrane. In Munc18 $\mathrm{c}^{+/+}$or Munc18 $\mathrm{c}^{+/-}$cells, 10 or $100 \mathrm{nM}$ insulin was required for maximal externalization of GLUT4 (Figures 8, A and C), even though $1 \mathrm{nM}$ insulin was sufficient for maximal induction of GLUT4 movement to the cell periphery (Figure 8B). However, in Munc18 $\mathrm{c}^{-/-}$adipocytes, both GLUT4 translocation to the cell periphery and GLUT4 externalization were maximal at $1 \mathrm{nM}$ insulin (Figure 8, B and C). Thus, sensitivity to the induction of GLUT4 externalization by insulin stimulation was enhanced in Munc $18 \mathrm{c}^{-/-}$adipocytes compared with Munc18 $\mathrm{c}^{+/+}$or Munc18 $\mathrm{c}^{+/-}$cells, although the maximal responses did not differ significantly among the 3 genotypes. Furthermore, we investigated the insulin-stimulated glucose uptake in adipocytes of each genotype. One hundred nanomolar insulin was required for the remarkable increase of glucose

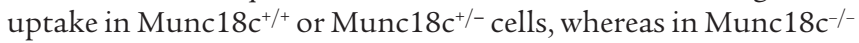
adipocytes, $1 \mathrm{nM}$ insulin induced almost the same increase in glucose uptake as did $100 \mathrm{nM}$ insulin (Figure 9). These results indicate that not only externalization of GLUT4 but also glucose uptake are enhanced in Munc18 $\mathrm{c}^{-/-}$adipocytes compared with Munc18 $\mathrm{c}^{+/+}$or Munc18c $\mathrm{c}^{+/-}$cells.

To further confirm the observed effects of Munc18c deficiency in adipocytes, we restored Munc18c expression in Munc18 $\mathrm{c}^{-/-}$ cells by infection with the adenovirus containing Munc18c that we have used previously (6). Restoration of Munc18c expression in the Munc $18 \mathrm{c}^{-/-}$adipocytes increased the abundance of syntaxin 4 to the level apparent in wild-type cells (Figure 10A). At this time, it seemed that the amount of Munc18c in Munc18 $\mathrm{c}^{-/-}$cells by infec-

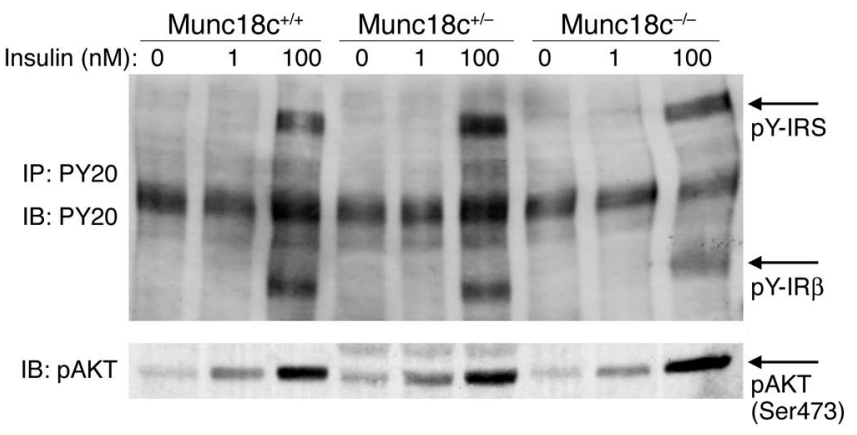

\section{Figure 6}

Lack of effect of Munc18c deficiency on proximal insulin signaling in

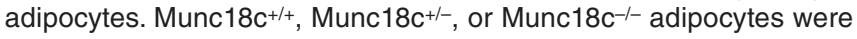
deprived of serum for 2 hours and then stimulated with insulin (1 or $100 \mathrm{nM}$ ) for 5 minutes. For detection of tyrosine-phosphorylated forms of IRS ( $p Y-I R S)$ and the $\beta$ subunit of the insulin receptor ( $p Y-I R \beta)$, cell lysates were subjected to immunoprecipitation and subsequent immunoblot analysis with mAb PY20 to phosphotyrosine (upper panel). For detection of serine-phosphorylated Akt, cell lysates were subjected to immunoblot analysis with antibodies specific for Akt phosphorylated on serine 473 (lower panel). 
A

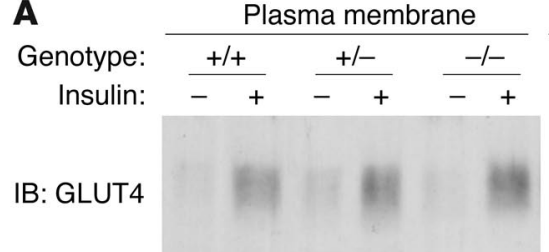

B

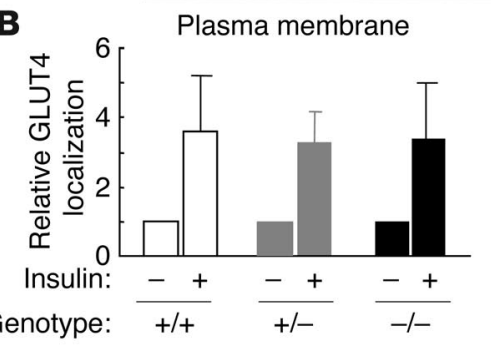

Intracellular membranes
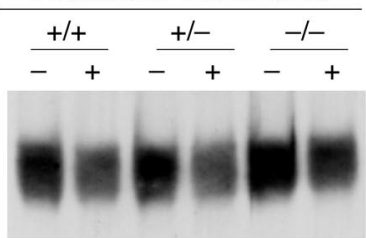

Intracellular membranes
1.2

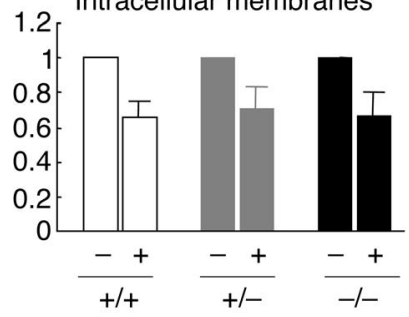

\section{Figure 7}

Insulin-stimulated translocation of endogenous GLUT4 to the plasma membrane in MEF-derived adipocytes. (A) Munc18 $\mathrm{c}^{+/+}$, Munc $18 \mathrm{c}^{+/-}$, or Munc $18 \mathrm{c}^{-/-}$adipocytes were deprived of serum for 2 hours and then stimulated with $100 \mathrm{nM}$ insulin for 20 minutes. Cell homogenates were subjected to subcellular fractionation, and plasma membrane and intracellular membrane fractions were subjected to immunoblot analysis with antibodies to GLUT4. (B) Immunoblot band intensity of GLUT4 was quantitated using NIH Image software and was expressed relative to the abundance of GLUT4 without insulin in cells of each genotypes. Data are mean \pm SE of values from 3 or 4 independent experiments. tion with adenovirus containing Munc18c was more abundant than that of endogenous Munc18c in Munc18c $\mathrm{c}^{+/+}$cells as determined by Western blot analysis (Figure 10A, upper panel). However, we suspected that this may have been be due to the much higher level of expression of adenovirus-mediated Munc18c proteins in undifferentiated cells which are scattered among differentiated adipocytes because of high efficiency of adenovirus infection of undifferentiated cells. Therefore, we investigated the expression level of Munc18c in adipocytes or in undifferentiated cells with immunofluorescence staining with anti-Munc18c antibody and confirmed that the abundance of adenovirus-mediated Munc18c proteins in Munc18 $\mathrm{c}^{-/-}$adipocytes was almost the same as that of endogenous Munc18c in Munc18 $\mathrm{c}^{+/+}$adipocytes (Figure 10B, arrows) and that Munc18c proteins are expressed in much greater quantities in undifferentiated cells (Figure 10B, arrowhead). Furthermore, restoration of Munc18c in Munc18c $\mathrm{c}^{-/}$adipocytes expressing GLUT4-myc7-GFP reduced the insulin sensitivity of GLUT4 externalization in Munc18 $\mathrm{c}^{-/-}$cells to a level similar to that apparent in wild-type adipocytes, without affecting the extent of GLUT4 movement to the cell periphery (Figure 10, C and D). These results thus confirmed that the insulin-induced fusion of GLUT4-containing vesicles with the plasma membrane and the consequent externalization of GLUT4, but not the translocation of these vesicles to the cell periphery, were enhanced by Munc18c deficiency in mouse adipocytes.

Insulin-stimulated GLUT4 externalization is wortmannin resistant in Munc18c-/- cells. Activation of a PI3K-dependent pathway is required for insulin-stimulated exocytosis of GLUT4-containing vesicles (18-20). In Munc18c $\mathrm{c}^{+/+}$adipocytes expressing GLUT4myc7-GFP, the PI3K inhibitor wortmannin (100 nM) inhibited by approximately $50 \%$ the GLUT4 externalization induced by 100 $\mathrm{nM}$ insulin (Figure 11, A and C). This observation is consistent with the previous finding that the half-maximal concentration of wortmannin for inhibition of insulin-stimulated GLUT4 insertion into the plasma membrane in 3T3-L1 mouse adipocytes is 80 $\mathrm{nM}$ (21). However, the insulin-stimulated movement of GLUT4 to the cell periphery in Munc18 $\mathrm{c}^{+/+}$cells was not inhibited by 100 $\mathrm{nM}$ wortmannin (Figure 11, $\mathrm{A}$ and $\mathrm{B}$ ), which is consistent with the previous observation that microtubule-dependent movement of GLUT4 elicited by insulin is insensitive to $100 \mathrm{nM}$ wortmannin (22). Whereas $100 \mathrm{nM}$ wortmannin inhibited insulin-stimulated GLUT4 externalization in WT cells, it did not do so in Munc18c-/- adipocytes (Figure 11, A and C), which suggests that the wortmannin-sensitive step of the insulin signaling pathway that regulates the fusion of GLUT4-containing vesicles with the plasma membrane and GLUT4 externalization involves Munc18c.

Phosphatidylinositol 3-phosphate induces GLUT4 externalization in Munc18c/- adipocytes. Given that we could not exclude the possibility that the insulin signaling pathway that is operative at $1 \mathrm{nM}$ hormone and is insensitive to $100 \mathrm{nM}$ wortmannin might also be required for GLUT4 externalization, we reconstituted the exocytosis of GLUT4-containing vesicles without insulin. The insulininduced formation of phosphatidylinositol 3-phosphate (PI3P), which is mediated by the activation of TC10, is resistant to $100 \mathrm{nM}$ wortmannin (23); PI3P was recently shown to trigger the movement of GLUT4-containing vesicles to the plasma membrane, but not glucose transport, in insulin-responsive cells (23). Exogenous delivery of PI3P with a polyamine carrier induced GLUT4 movement to the cell periphery in approximately $40-50 \%$ of Munc $18 \mathrm{c}^{+/+}$ or Munc18 $\mathrm{c}^{-/-}$adipocytes (Figure 12, A and B). However, PI3P also induced GLUT4 externalization in Munc18 $\mathrm{c}^{-/-}$adipocytes but not in wild-type cells (Figure 12, A and C). Thus, a large proportion (approximately 80\%) of GLUT4 molecules that were translocated to the cell periphery in Munc18 $\mathrm{c}^{-/-}$adipocytes in response to PI3P was externalized in the absence of insulin (Figure 12D). These results suggest that the insulin-induced formation of PI3P is sufficient to trigger both the translocation of GLUT4-containing vesicles to the cell periphery and their fusion with the plasma membrane in the absence of Munc18c.

\section{Discussion}

Munc18 isoforms are mammalian members of the family of Sec1and UNC-18-related proteins that are highly conserved from yeast to mammals. This protein family is thought to play important roles in SNARE-dependent membrane trafficking and membrane fusion reactions (24). Three Munc18 isoforms, Munc18a (Munc18-1), Munc18b, and Munc18c, have been identified to date $(11-13,25)$. Munc18a is mainly expressed in neuronal cells, and Munc18a $\mathrm{a}^{-/-}$mice die immediately after birth as a result of respiratory insufficiency (14). Furthermore, deletion of the Munc18a gene leads to a complete loss of neurotransmitter release from synaptic vesicles without an apparent effect on brain structure. We have now shown that deletion of the gene for the widely expressed isoform Munc18c (25) causes intrauterine growth retardation and 
A

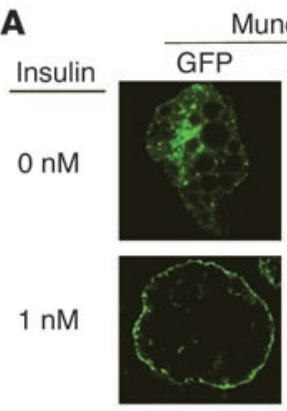

$100 \mathrm{nM}$

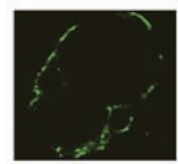

B

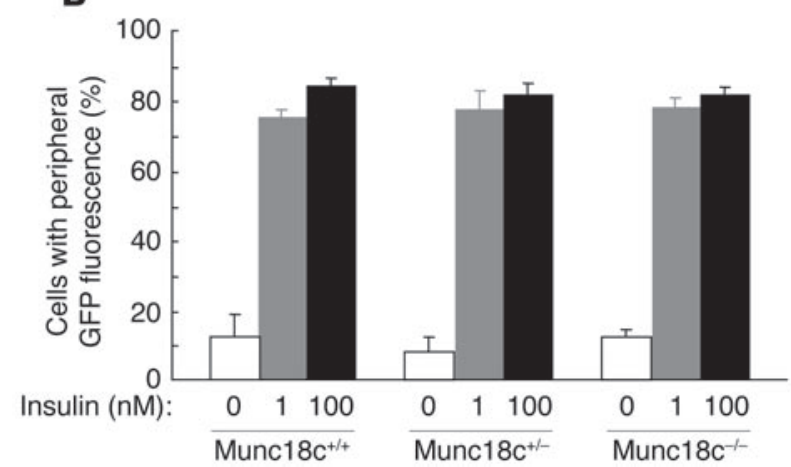

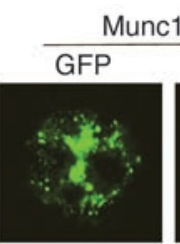

Munc18c
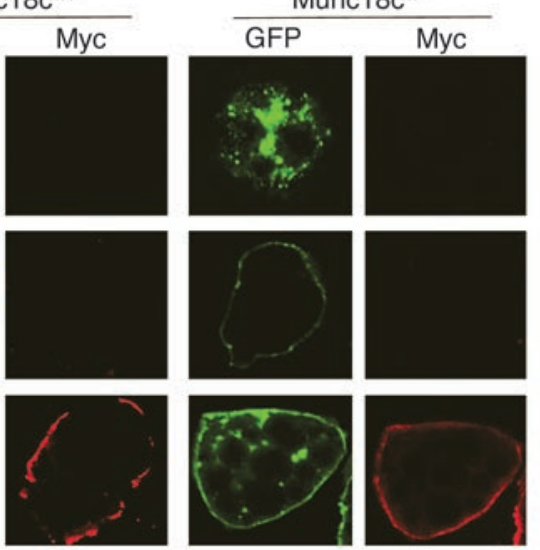

C
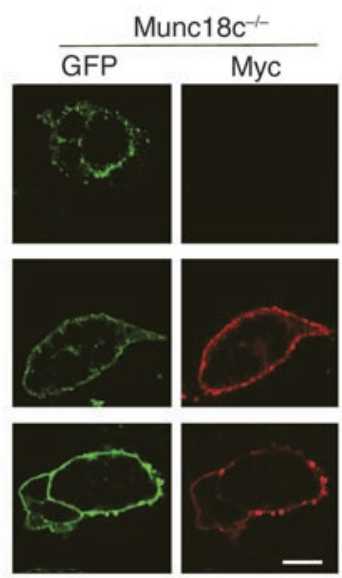

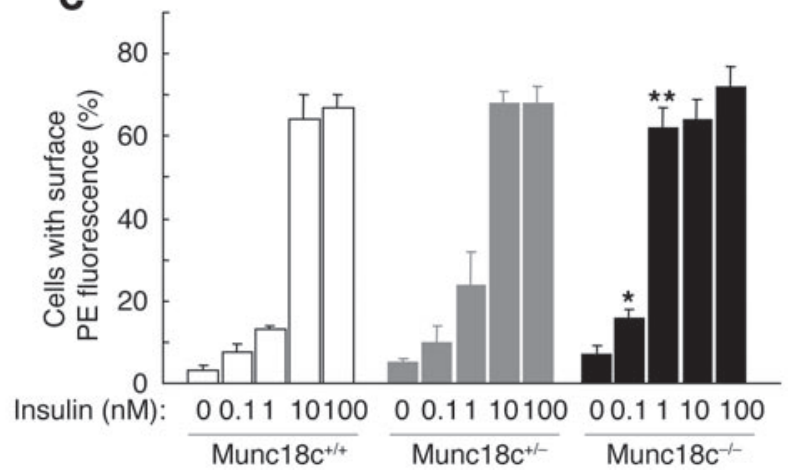

Figure 8

Enhancement of insulin-stimulated GLUT4 externalization, but not of GLUT4 translocation to the cell periphery, in Munc18c ${ }^{-/-}$adipocytes. (A)

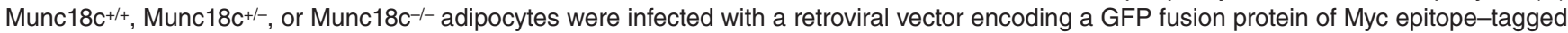
GLUT4 (GLUT4-myc7-GFP). The cells were stimulated with the indicated concentrations of insulin for 20 minutes, fixed, and subjected to indirect immunofluorescence staining with antibodies to the Myc tag and PE-conjugated secondary antibodies in order to detect externalized GLUT4 (red). GLUT4 translocation to the cell periphery was detected by GFP fluorescence (green) on analysis of the cells by confocal microscopy. Scale bar: $10 \mu \mathrm{m}$. (B) Movement of GLUT4 to the cell periphery in experiments similar to that shown in A was quantitated by determination of the percentage of GFP-positive cells that manifested GFP fluorescence at the cell periphery. Data are mean \pm SE of values from 3 separate experiments, with 1,000 GFP-positive cells being examined in each experiment. (C) GLUT4 externalization in experiments similar to that shown in A was quantitated by determination of the percentage of GFP-positive cells that exhibited PE fluorescence at the cell surface. Data are mean \pm SE of values from 4-6 independent experiments, with 1,000 GFP-positive cells being examined in each experiment. ${ }^{*} P<0.05$, ${ }^{\star *} P<0.001$ versus the corresponding values for Munc $18 \mathrm{c}^{+/+}$cells (Student's $t$ test).

disorganization of brain structure in mice. The characteristics of homozygous knockout mice thus suggest that Munc18a is essential for neurotransmitter secretion and that Munc18c is important for normal development of embryos, including that of the CNS.

Overexpression of Munc18c in 3T3-L1 adipocytes was previously shown to inhibit insulin-stimulated GLUT4 translocation to the plasma membrane $(6,7)$. In addition, microinjection of antibodies to Munc18c into 3T3-L1 cells stimulated GLUT4 translocation (26). These observations thus suggested that Munc18c plays an inhibitory role in insulin-induced GLUT4 translocation. In contrast, the introduction into adipocytes of a peptide fragment of Munc18c (18c/pep3) that inhibits the binding of Munc18c to syntaxin 4 resulted in inhibition of insulin-stimulated integration of GLUT4 vesicles into the plasma membrane (15), which suggests that the interaction between Munc18c and syntaxin 4 is required for this process. However, results from recent studies using crystallography have shown that this peptide (18c/pep3) is derived from a region that does not directly contact syntaxin but represents
Rab or Rab effector binding sites whose conformations are critical to syntaxin binding $(27,28)$. Thus, this peptide may induce some other effects on Rab or Rab effectors in addition to disrupting the association between synatxin 4 and Munc18c. These contradictory data have thus left unclear the precise role of Munc18c in insulin-stimulated GLUT4 translocation. In the present study, ablation of Munc18c in adipocytes by gene knockout did not affect insulin-stimulated GLUT4 trafficking to the cell periphery, but it enhanced the fusion of GLUT4-containing vesicles with the plasma membrane. We believe that the gene knockout methods used in our studies to determine the physiological functions of Munc18c in the insulin-stimulated GLUT4 translocation in adipocytes can lead to more definitive results than those of previous studies using other methods. In addition to its role in GLUT4 exocytosis in insulinsensitive cells, Munc18c is implicated in the regulation of a SNARE complex that functions in the $\mathrm{Ca}^{2+}$-triggered exocytosis of densecore vesicles in platelets $(29,30)$. Introduction into platelets either of antibodies to Munc18c or of Munc18c peptides that inhibit the 


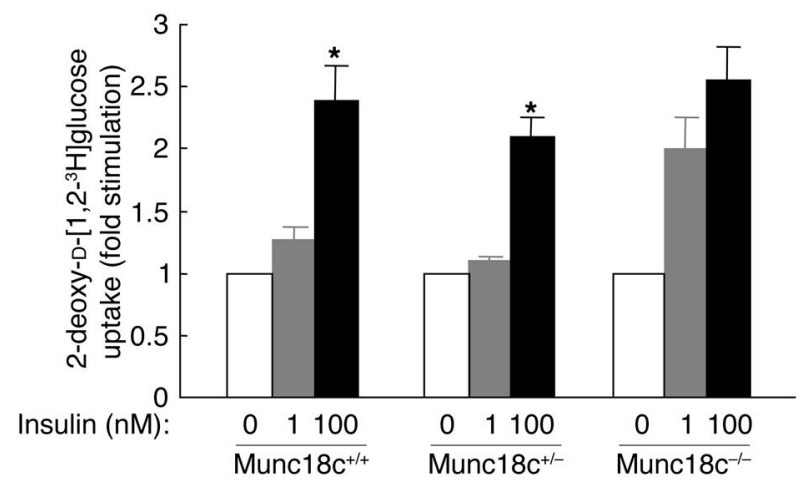

binding of Munc18c to syntaxin 4 enhanced $\mathrm{Ca}^{2+}$-induced exocytosis (30), which suggests that Munc18c plays a negative role in $\mathrm{Ca}^{2+}-$ induced secretion in these cells. Furthermore, Munc18c localized at the basal membrane of pancreatic acinar cells inhibits amylase release at the basal cell surface under physiological conditions (31). These observations of secretion in platelets and acinar cells are consistent with our present results showing that Munc18c negatively regulates insulin-induced GLUT4 exocytosis in adipocytes.

Stimulation of MEF-derived adipocytes with insulin at concentrations of 1 and $100 \mathrm{nM}$ induced similar levels of GLUT4 movement to the cell periphery. In contrast, GLUT4 externalization

\section{Figure 9}

Enhancement of insulin-stimulated glucose transport in Munc18c-/adipocytes. Uptake of 2-deoxy-D-[1,2-3H]glucose was assayed in Munc $18 \mathrm{c}^{+/+}$, Munc18 $\mathrm{c}^{+/-}$, or Munc $18 \mathrm{c}^{-/-}$adipocytes stimulated with the indicated concentrations of insulin. Data are mean \pm SE of 6 independent experiments and are expressed as fold stimulation of glucose uptake relative to that without insulin. ${ }^{*} P<0.01$ versus cells stimulated with $1 \mathrm{nM}$ insulin (Student's $t$ test).
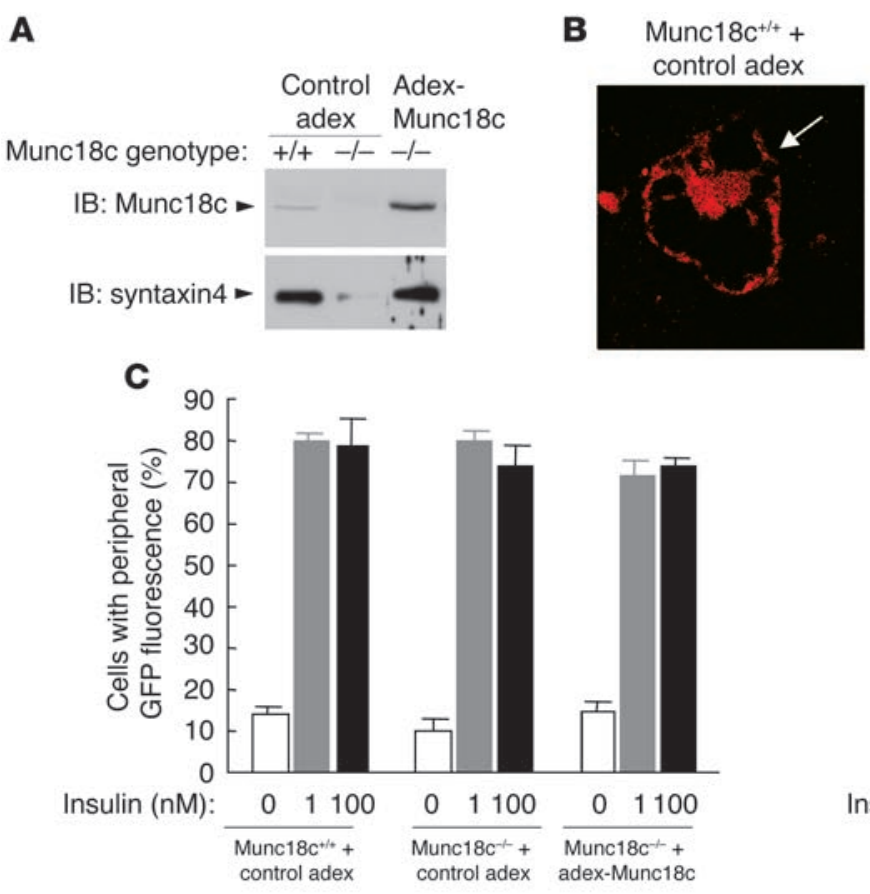

required $100 \mathrm{nM}$ insulin in wild-type adipocytes. We have obtained similar results with 3T3-L1 adipocytes (M. Yoshikawa, Y. Tamori, and M. Kasuga, unpublished observations). Our observations that $100 \mathrm{nM}$ wortmannin inhibited the insulin-induced externalization of GLUT4 but not GLUT4 translocation to the plasma membrane in Munc18 $\mathrm{c}^{+/+}$adipocytes, and that it did not affect GLUT4 externalization in Munc18 $\mathrm{c}^{-/-}$cells, suggest that insulininduced trafficking of GLUT4 from intracellular compartments to the plasma membrane is insensitive to $100 \mathrm{nM}$ wortmannin and that Munc18c plays a negative role downstream of PI3K activation in the fusion of GLUT4 vesicles with the plasma membrane.

Figure 10

Normalization both of syntaxin4 expression and of the insulin sensitivity of GLUT4 externalization in Munc18c ${ }^{-/-}$adipocytes by restoration of Munc18c expression. (A) Syntaxin4 expression. Munc18c $\mathrm{c}^{+/+}$or Munc18 $\mathrm{c}^{-/-}$adipocytes were infected with an adenoviral vector for Munc18c (adexMunc18c) or with the corresponding empty vector (control adex), as indicated. After 2 days, cell lysates were subjected to immunoblot analysis with antibodies to Munc18c (upper panel) or to syntaxin4 (lower panel). (B) Immunofluorescence microscopic analysis of Munc18c in adipocytes.

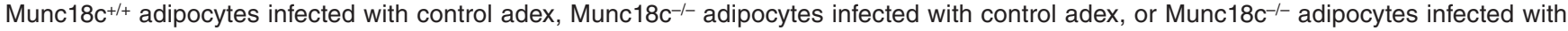
adex-Munc18c at an MOI of 5 were fixed, permeabilized, subjected to immunofluorescence staining with antibodies to Munc18c, and analyzed by confocal microscopy. Arrows mark the localizations of differentiated adipocytes, and the arrowhead indicates undifferentiated cells. Scale bar: $10 \mu \mathrm{m}$. (C and D) GLUT4 translocation and externalization. Cells infected as in A were assayed for the translocation (C) and externalization (D) of GLUT4 in response to insulin as described in Figure 8. Data are mean \pm SE of values from 3 separate experiments. ${ }^{\star} P<0.05$ versus the value for Munc18 $18 \mathrm{c}^{-1-}$ cells infected with control adex and stimulated with $1 \mathrm{nM}$ insulin (Student's $t$ test). 
A

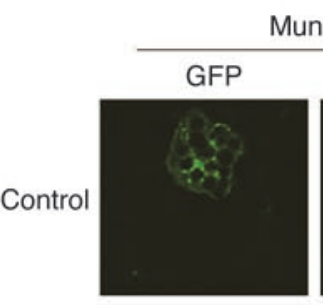

Munc18c $\mathrm{c}^{+/+}$
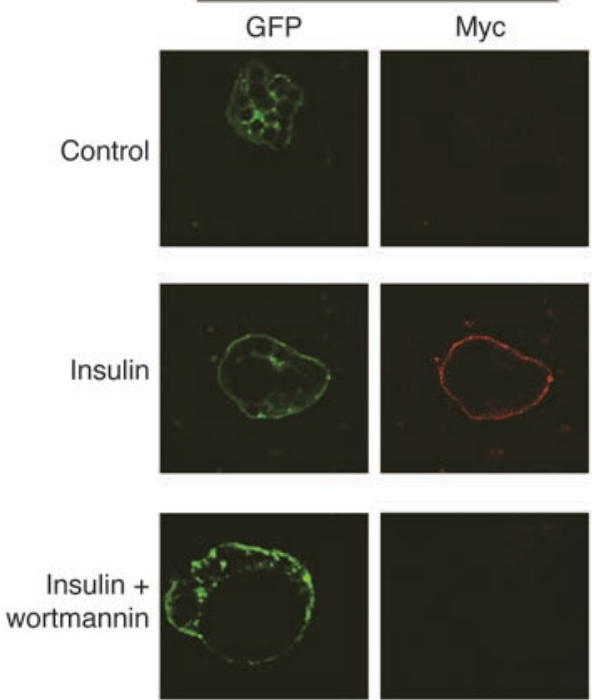

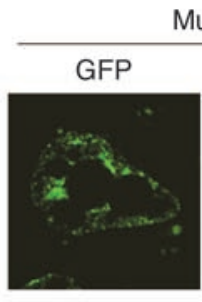

Munc18 $\mathrm{c}^{-1-}$
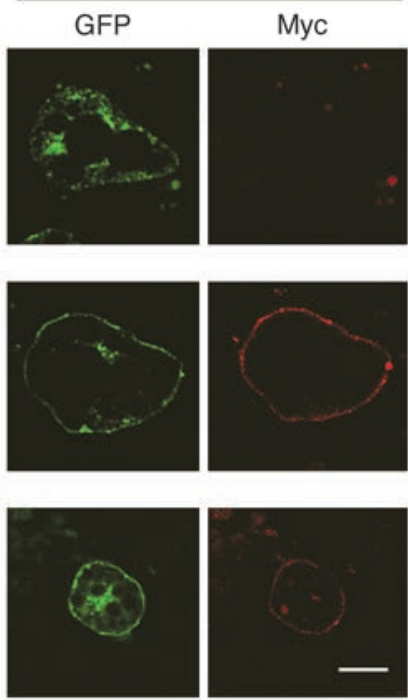

B

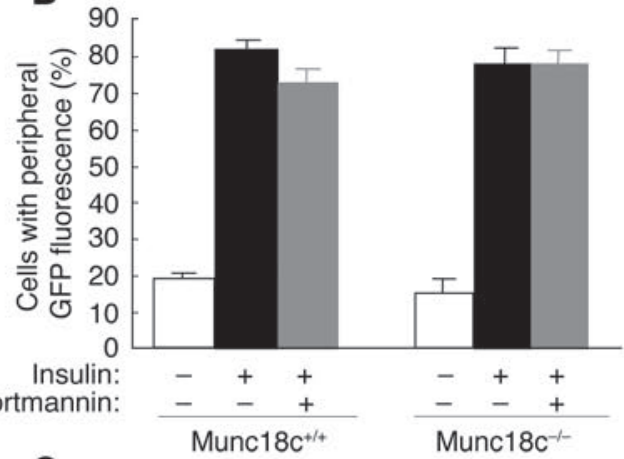

C

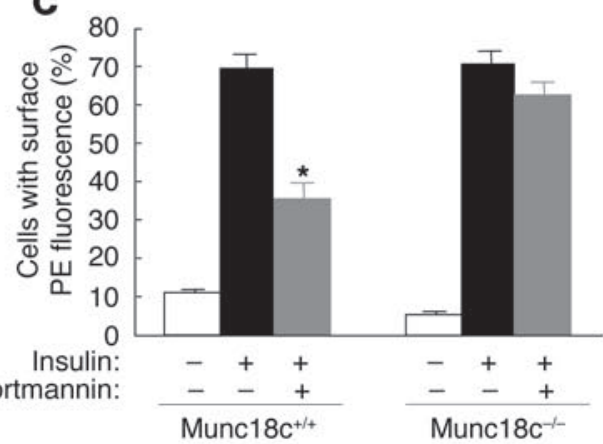

Figure 11

Wortmannin insensitivity of insulin-induced GLUT4 externalization in Munc18c $\mathrm{c}^{-/-}$adipocytes. (A) Munc18c $\mathrm{c}^{+/+}$or Munc18c $\mathrm{c}^{-/-}$adipocytes expressing GLUT4-myc7-GFP were incubated for 20 minutes in the absence or presence of $100 \mathrm{nM}$ insulin and then for 20 minutes in the additional absence or presence of $100 \mathrm{nM}$ wortmannin. The cells were then analyzed as described in Figure 8A. Scale bar: $10 \mu \mathrm{m}$. (B) Quantitation of GLUT4 movement to the cell periphery in experiments similar to that shown in A. Data are mean \pm SE of values from 6 separate experiments, with 100 GFPpositive cells being examined in each experiment. (C) Quantitation of GLUT4 externalization in experiments similar to that shown in A. Data are mean \pm SE of values from 6 independent experiments, with 100 GFP-positive cells being examined in each experiment. ${ }^{*} P<0.001$ versus the corresponding value for cells exposed to insulin alone (Student's $t$ test).

The wortmannin insensitivity of GLUT4 translocation observed in the present study is consistent with the previous observation that insulin induces the movement of GLUT4-containing intracellular membranes along microtubules by a mechanism that is insensitive to $100 \mathrm{nM}$ wortmannin (22). Furthermore, insulin-induced generation of PI3P in a manner that is resistant to $100 \mathrm{nM}$ wortmannin has been shown to contribute to GLUT4 trafficking to the plasma membrane (23). We confirmed this result by showing that PI3P induced not only the movement of GLUT4 to the plasma membrane but also GLUT4 externalization in Munc18 $\mathrm{c}^{-/-}$cells.

The total amount of syntaxin 4 was decreased in Munc18 $\mathrm{c}^{-/-}$ adipocytes, whereas the abundance of neither SNAP23 nor VAMP2 was altered. This specific downregulation of syntaxin 4 is consistent with the previous observation that the abundance of syntaxin1, which forms a complex with Munc18-1, was reduced by approximately $50 \%$ in the adrenal glands of Munc18-1-/- mice (32). Furthermore, the abundance of the syntaxin-like protein Tlg2p, which associates with the Munc18 homolog Vps45p, was also downregulated to undetectable levels by rapid proteasomemediated degradation in yeast cells that lack Vps45p (33). These various results suggest that Munc18c may protect syntaxin 4 from proteasome-mediated degradation in adipocytes.

Syntaxin $4^{+/-}$mice are insulin resistant (34). Glucose transport as well as GLUT4 translocation to the plasma membrane in skeletal muscle of these mice are thus reduced during hyperinsulinemiceuglycemic clamp procedures. These results suggest that downregulation of syntaxin 4 expression results in impairment of insulin-stimulated GLUT4 translocation in skeletal muscle. Furthermore, Munc18c transgenic mice manifest whole-body insulin resistance that results from a reduction in the extent of glucose uptake in skeletal muscle and white adipose tissue (16). This insulin resistance was reversed by the simultaneous overexpression of syntaxin4, which suggests that a relative excess of Munc18c compared with the amount of syntaxin 4 causes insulin resistance. We have now shown that the amount of Munc18c-free syntaxin 4 is greater in Munc18 $\mathrm{c}^{-/-}$adipocytes than in Munc18 $\mathrm{c}^{+/+}$cells, even though the total amount of syntaxin 4 was reduced in the former. These results thus suggest that Munc18c-free syntaxin 4 is able to associate with SNAP23 and VAMP2 and to participate in the fusion of GLUT4 vesicles with the plasma membrane. Consistent with the notion that the relative expression levels of syntaxin 4 and Munc18c affect insulin sensitivity, Munc18c is upregulated without a change in syntaxin 4 abundance in the skeletal muscle either of transgenic mice that overexpress lipoprotein lipase specifically in skeletal muscle or of mice fed a high-fat diet, both of which are insulin resistant (35).

Together, our data demonstrate that insulin regulates the 2 distinct steps in the exocytosis of GLUT4-containing vesicles by different mechanisms. The first step is the translocation of GLUT4containing vesicles from intracellular storage sites to the cell periphery, and the second step is the fusion of these vesicles with the plasma membrane and GLUT4 externalization. These steps 
A

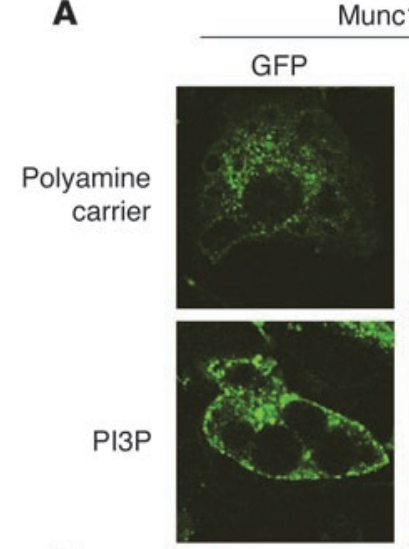

B

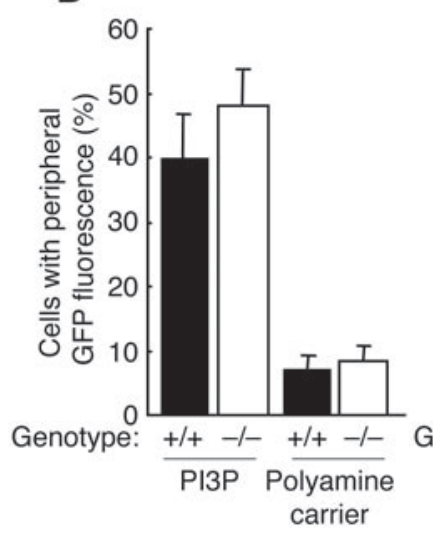

differ with regard to insulin concentration requirement, sensitivity to wortmannin, and involvement of Munc18c. On the basis of our observations, we suggest that insulin $(100 \mathrm{nM})$ induces the release of syntaxin 4 from its complex with Munc18c in a manner sensitive to wortmannin, resulting in fusion with the plasma membrane of GLUT4-containing vesicles that have been translocated from the cell interior to the periphery. The amount of Munc18c-free syntaxin 4 is thus an important determinant of the rate of glucose transport and is a potential target for the development of therapeutics to increase the glucose transport rate in adipose tissues or skeletal muscles in individuals with type 2 diabetes mellitus.

\section{Methods}

Antibodies and cDNA clones. Rabbit polyclonal antibodies to Munc18c, to syntaxin4, to SNAP23, and to GLUT4 have been described previously $(4,6,9)$. Rabbit polyclonal antibodies to rat Munc18c and to rat syntaxin2 were kindly provided by A. Imai (Nippon Dental University, Niigata, Japan) and M.K. Bennett (University of California, Berkeley, California, USA), respectively. Rabbit polyclonal antibodies to VAMP2 were obtained from Synaptic Systems. Mouse mAbs to phosphotyrosine (PY20) and rabbit polyclonal antibodies to Akt phosphorylated on serine 473 were from BD Biosciences and Cell Signaling Technology Inc., respectively. Mouse mAbs to c-Myc were from Santa Cruz Biotechnology Inc. Mouse mAbs to GFP (JL-8) were from BD Biosciences. The $\mathrm{mAb} \mathrm{A} 6 \mathrm{C}$, which immunoprecipitates only Munc18c-free syntaxin4, was produced by injection of mice with a recombinant protein comprising amino acids $1-136$ of rat syntaxin 4 . Mouse Munc18c and SNAP23 cDNAs were isolated as described previously $(4,6)$, and rat syntaxin 4 cDNA was kindly provided by R.H. Scheller (Stanford University, Stanford, California, USA).

\section{Figure 12}

PI3P-induced externalization of GLUT4 in Munc18c-/- adipocytes. (A) Munc $18 \mathrm{c}^{+/+}$or Munc18c-/- adipocytes expressing GLUT4myc7-GFP were exposed for 7 minutes to a mixture of PI3P and polyamine carrier or to the carrier alone and were then analyzed as described in Figure 8A. Scale bar: $10 \mu \mathrm{m}$. (B-D) Quantitation of GLUT4 movement to the cell periphery (B), of GLUT4 externalization (C), and of the proportion of GLUT4 molecules translocated to the cell periphery that undergo externalization (the percentage of cells with peripheral GFP fluorescence that also show surface PE fluorescence) (D) in experiments similar to that shown in $\mathbf{A}$. Data are mean \pm SE of values from 3 independent experiments. ${ }^{*} P<0.01,{ }^{* *} P<0.001$ versus the corresponding values for Munc18c $\mathrm{c}^{+/+}$cells.
Generation of Munc18c $\mathrm{c}^{-/-}$mice. A 16-kb DNA fragment containing the translation initiation codon (ATG) of Munc18c was cloned from a 129/SvJ mouse genomic library with the use of a 5 ' fragment of the mouse Munc18c cDNA as a probe. This genomic fragment did not contain other exons. The exon containing the translation initiation codon of Munc18c was then replaced with the neomycin resistance gene (neo) without a promoter. To promote efficient translation of neo transcripts, we inserted an IRES sequence in the $5^{\prime}$ flanking region of the gene (Figure 1 ). The targeting vector was introduced into 129/Ola-derived ES cells by electroporation, and the cells were then cultured in the presence of G418 $(150 \mu \mathrm{g} / \mathrm{ml})$. Southern blot analysis identified 4 cell clones that had undergone homologous recombination. One line of chimeric mice was generated by injecting cells of these clones into C57BL/6J blastocysts. The chimeras were then mated with $\mathrm{C} 57 \mathrm{BL} / 6 \mathrm{~J}$ mice to yield Munc18 $\mathrm{c}^{+/-}$animals. These mice were backcrossed to the C57BL/6J strain for 5 generations. Munc18 $\mathrm{c}^{+/-}$mice

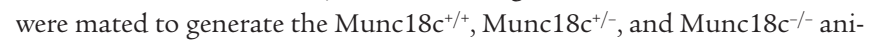
mals used in the present study. All animal experiments were approved by the animal ethics committee of Kobe University Graduate School of Medicine (approval number P-021205R).

Preparation and culture of adipocytes derived from MEFs. For isolation of MEFs, the head, limbs, and viscera were removed from 13.5-dpc mouse embryos, and the remaining tissue was minced and then digested for 60 minutes at $37^{\circ} \mathrm{C}$ with type 1 collagenase $(4 \mathrm{mg} / \mathrm{ml}$ ) (Worthington Biochemical Corp.) in a mixture of PBS and DMEM (1:1, vol/vol) containing $5 \%$ BSA. Cells were collected and grown in DMEM supplemented with $10 \%$ FBS, penicillin-streptomycin, and $200 \mu \mathrm{M}$ ascorbic acid. For induction of adipocyte differentiation, confluent MEFs were incubated first for 2 days with $10 \mathrm{nM}$ insulin (Sigma-Aldrich) and $1 \mathrm{nM}$ triiodothyronine (Sigma-Aldrich) and then for 2 days in the additional presence of $250 \mathrm{nM}$ 
dexamethasone (Sigma-Aldrich), $0.5 \mathrm{mM}$ isobutylmethylxanthine (SigmaAldrich), and $125 \mathrm{nM}$ indomethacin (Wako Pure Chemical Industries Ltd.). The cells were then returned to the original MEF culture medium where they were incubated for 8 days, with refreshment of the medium every 2 days, before being subjected to experiments.

Production of and infection with retrovirus encoding GLUT4-myc7-GFP. Platinum-E (PLAT-E) ecotropic packaging cells were transfected with the retrovirus vector PMX-GLUT4-myc7-GFP, which was kindly provided by H.F. Lodish (Massachusetts Institute of Technology, Cambridge, Massachusetts, USA) (17) using transfection reagent FuGENE 6 (Roche Diagnostics) according to the manufacturer's recommendation. Media containing recombinant retroviruses were harvested 48 hours after transfection. For infection to the target cells, $2 \times 10^{5} \mathrm{MEF}$ s were cultured in $10 \%$ FBS-DMEM containing $1 \mathrm{ml}$ of media containing retrovirus in $60-\mathrm{mm}$ culture dishes for 24 hours. The recombinant retrovirus that we used was shown to be expressed with an efficacy of greater than $80 \%$ in MEF-derived adipocytes, as assessed by GFP fluorescence.

Preparation of and infection with adenovirus containing Munc18c. Recombinant adenovirus vectors containing Munc18c were generated as described previously (6). Eight days after induction of differentiation, MEF-derived adipocytes were infected with the adenovirus at an MOI of 5 . The adipocytes were subjected to experiments 2 days after infection.

Northern blot analysis. Total RNA was extracted from adipocytes with the use of an RNeasy kit (QIAGEN), and 30- $\mu$ g portions of the isolated RNA were subjected to Northern blot analysis with $\left[{ }^{32} \mathrm{P}\right]$-labeled probes prepared with a Rediprime II random-primer labeling system (Amersham Biosciences). Probes for mouse Munc18c and SNAP23 mRNAs were generated by amplification of cDNA fragments by PCR. Probes for mouse syntaxin 4 and VAMP2 mRNAs were obtained by reverse transcription with total RNA extracted from mouse skeletal muscle followed by PCR. Probes for mouse Munc18b mRNA were obtained by reverse transcription with total RNA extracted from mouse adipose tissues followed by PCR. Autoradiograms of blots were visualized with a BAS-2000 image analyzer (Fujifilm).

Subcellular fractionation. Subcellular fractionation of adipocytes was performed as described previously (36) with minor modifications. The cells were homogenized in TES buffer (20 mM Tris-HCl [pH 7.4], 1 mM EDTA, $225 \mathrm{mM}$ sucrose), and the homogenate was centrifuged at $16,000 \mathrm{~g}$ for 15 minutes. The resulting pellets were resuspended, layered on top of a $1.12-\mathrm{M}$ sucrose cushion, and centrifuged at 101,000 $\mathrm{g}$ for 20 minutes, after which the plasma membrane fraction was collected from the interface of the 2 solutions. The intracellular membrane fraction was obtained by centrifugation of the initial supernatant at 212,000 $\mathrm{g}$ for 60 minutes. Plasma membrane and intracellular membrane fractions were subjected to immunoblot analysis with antibodies to GLUT4. Immunoblot band intensity of GLUT4 was quantitated using NIH Image software (http://rsb.info.nih.gov/nih-image).

Immunofluorescence microscopy. Adipocytes expressing GLUT4-myc7-GFP were fixed with PBS containing 4\% paraformaldehyde, washed with PBS containing $100 \mathrm{mM}$ glycine, and exposed to PBS containing 5\% BSA. Externalized GLUT4-myc7-GFP was visualized without cell permeabilization by indirect immunofluorescence staining with an $\mathrm{mAb}$ to $\mathrm{c}-\mathrm{Myc}$ and PE-conjugated goat antibodies to mouse IgG (Jackson ImmunoResearch Laboratories Inc.). The cells were then examined for PE and GFP fluorescence with a Zeiss Axiophot confocal laser scanning microscope (LSM5 PASCAL version 3; Carl Zeiss). For the detection of Munc18c protein, adipocytes fixed with $4 \%$ paraformaldehyde were permeabilized with $0.5 \%$ Triton X-100 and incubated with PBS containing 5\% BSA, then visualized by indirect immunofluorescence staining with antibodies to Munc18c and Texas redconjugated donkey antibodies to rabbit IgG (Amersham Biosciences).

Immunoprecipitation and immunoblot analysis. Whole cell lysates were prepared by detergent solubilization with a lysis buffer containing $25 \mathrm{mM}$ Tris-HCl (pH 7.4), $150 \mathrm{mM} \mathrm{NaCl}, 1 \mathrm{mM}$ EDTA, 1\% Triton X-100, $1 \mathrm{mM}$ sodium vanadate, $50 \mathrm{mM} \mathrm{NaF}, 10 \mathrm{mM}$ sodium pyrophosphate, and $1 \mathrm{mM}$ PMSF. The lysates were subjected to immunoprecipitation by incubation for 2 hours at $4{ }^{\circ} \mathrm{C}$ with protein G-Sepharose (Amersham Biosciences) conjugated with the indicated antibodies. The beads were washed 3 times before immunoblot analysis. Immunoblot band intensity was quantitated with NIH Image software.

Assays of 2-deoxy-D-glucose transport. Adipocytes cultured in 12-well plates were deprived of serum by incubation for 2 hours. The cells were then incubated with $1 \mathrm{nM}$ or $100 \mathrm{nM}$ insulin for 20 minutes in $450 \mu \mathrm{l}$ of KRH buffer (25 mM HEPES-NaOH [pH 7.4], $120 \mathrm{mM} \mathrm{NaCl}, 5 \mathrm{mM} \mathrm{KCl}, 1.2 \mathrm{mM}$ $\mathrm{MgSO}_{4}, 1.3 \mathrm{mM} \mathrm{CaCl}_{2}$, and $1.3 \mathrm{mM} \mathrm{KH}_{2} \mathrm{PO}_{4}$ ). Glucose transport was initiated by the addition of $50 \mu \mathrm{l}$ of $\mathrm{KRH}$ buffer containing $0.5 \mathrm{mM}$ 2-deoxy-D-[1,2- $\left.{ }^{3} \mathrm{H}\right]$ glucose $(0.25 \mu \mathrm{Ci})$ to each well; after 5 minutes, transport was terminated by washing the cells 3 times with ice-cold KRH buffer. The cells were solubilized, and the incorporated radioactivity was measured by liquid scintillation counting.

Delivery of PI3P into cells. Unlabeled Carrier 3 (Echelon Research Laboratories) and PI3P (Cell Signals) were mixed at a molar ratio of 1:1 (final concentration of each, $200 \mu \mathrm{M}$ ), agitated, subjected to sonication, and incubated for 7 minutes at room temperature. The mixture was then added to the medium of adipocytes to a final concentration of $1 \mu \mathrm{M}$ PI3P (23), and, after 10 minutes, the cells were subjected to immunofluorescence microscopy.

Measurement of triglyceride content of adipocytes. The triglyceride content of isopropanol extracts prepared from adipocytes grown in 35- $\mathrm{mm}$ dishes was quantitated with an acetyl acetone-based colorimetric kit (Wako Pure Chemical Industries Ltd.).

Statistical analysis. All quantitative data were compared using Student's $t$ test.

\section{Acknowledgments}

We thank H.F. Lodish for pMX-GLUT4-myc7-GFP, M.K. Bennett for antibodies to syntaxin2, R.H. Scheller for rat syntaxin 4 cDNA, A. Imai for antibodies to rat Munc18c, T. Maffucci for technical advice on delivery of PI3P into adipocytes, and S. Shigeta for technical assistance. This work was supported by grants for the Intellectual Cluster Formation Project and the 21st Century COE Program, "Center of Excellence for Signal Transduction Disease: Diabetes Mellitus as a Model," from the Ministry of Education, Culture, Sports, Science, and Technology of Japan (to M. Kasuga).

Received for publication July 12, 2004, and accepted in revised form November 23, 2004.

Address correspondence to: Yoshikazu Tamori, Division of Diabetes and Digestive and Kidney Diseases, Department of Clinical Molecular Medicine, Kobe University Graduate School of Medicine, 7-5-1 Kusunoki-cho, Chuo-ku, Kobe 650-0017, Japan. Phone: 81-78-3825861; Fax: 81-78-382-2080; E-mail: tamori@med.kobe-u.ac.jp.

Motoyoshi Sakaue's present address is: School of Human Science and Environment, University of Hyogo, Himeji, Japan.
1. Holman, G.D., and Sandoval, I.V. 2001. Moving the insulin-regulated glucose transporter GLUT4 into and out of storage. Trends Cell Biol. 11:173-179.

2. Bryant, N.J., Govers, R., and James, D.E. 2002.
Regulated transport of the glucose transporter GLUT4. Nat. Rev. Mol. Cell Biol. 3:267-277.

3. Cheatham, B., et al. 1996. Insulin-stimulated translocation of GLUT4 glucose transporters requires
SNARE-complex proteins. Proc. Natl. Acad. Sci.U.S. A 93:15169-15173.

4. Araki, S., et al. 1997. Inhibition of the binding of SNAP-23 to syntaxin 4 by Munc18c. Biochem. 
Biophys. Res. Commun. 234:257-262.

5. Tellam,J.T., et al. 1997. Characterization of Munc-18c and syntaxin-4 in 3T3-L1 adipocytes. J. Biol. Chem. 272:6179-6186.

6. Tamori, Y., et al. 1998. Inhibition of insulin-induced GLUT4 translocation by Munc18c through interaction with syntaxin 4 in 3T3-L1 adipocytes. J. Biol. Chem. 273:19740-19746.

7. Thurmond, D.C., et al. 1998. Regulation of insulinstimulated GLUT4 translocation by Munc18c in 3T3L1 adipocytes. J. Biol. Chem. 273:33876-33883.

8. Rea, S., et al. 1998. Syndet, an adipocyte target SNARE involved in the insulin-induced translocation of GLUT4 to the cell surface. J. Biol. Chem. 273:18784-18792.

9. Kawanishi, M., et al. 2000. Role of SNAP23 in insulin-induced translocation of GLUT4 in 3T3-L1 adipocytes. Mediation of complex formation between syntaxin 4 and VAMP2. J. Biol. Chem. 275:8240-8247.

10. Shepherd, P.R., Withers, D.J., and Siddle, K. 1998. Phosphoinositide 3-kinase: the key switch mechanism in insulin signaling. Biochem. J. 333:471-490.

11. Hata, Y., Slaughter, C.A., and Südhof, T.C. 1993. Synaptic vesicle complex contains unc-18 homologue bound to syntaxin. Nature. 366:347-351.

12. Pevsner, J., Hsu, S.C., and Scheller, R.H. 1994. n-Sec1: a neural-specific syntaxin-binding protein. Proc. Natl. Acad. Sci. U. S. A. 91:1445-1449.

13. Garcia, E.P., Gatti, E., Butler, M., Burton, J., and De Camilli, P. 1994. A rat brain sec1 homologue related to Rop and UNC18 interacts with syntaxin. Proc. Natl. Acad. Sci. U. S. A. 91:2003-2007.

14. Verhage, M., et al. 2000. Synaptic assembly of the brain in the absence of neurotransmitter secretion. Science. 287:864-869.

15. Thurmond, D.C., Kanzaki, M., Khan, A.H., and Pessin, J.E. 2000. Munc18c function is required for insulin-stimulated plasma membrane fusion of GLUT4 and insulin-responsive amino peptidase storage vesicles. Mol. Cell. Biol. 20:379-388.

16. Spurlin, B.A., et al. 2003. Insulin resistance in tetracycline-repressible Munc18c transgenic mice. Diabetes. 52:1910-1917.

17. Bogan, J.S., McKee, A.E., and Lodish, H.F. 2001. Insulin-responsive compartments containing GLUT4 in 3T3-L1 and CHO cells: regulation by amino acid concentrations. Mol. Cell. Biol. 21:4785-4806.

18. Okada, T., Kawano, Y., Sakakibara, T., Hazeki, O., and Ui, M. 1994. Essential role of phosphatidylinositol 3-kinase in insulin-induced glucose transport and antilipolysis in rat adipocytes. Studies with a selective inhibitor wortmannin. J. Biol. Chem. 269:3568-3573.

19. Hara, K., et al. 1994. 1-Phosphatidylinositol 3-kinase activity is required for insulin-stimulated glucose transport but not for RAS activation in CHO cells. Proc. Natl. Acad. Sci. U. S. A. 91:7415-7419.

20. Cheatham, B., et al. 1994. Phosphatidylinositol 3-kinase activation is required for insulin stimulation of pp70 S6 kinase, DNA synthesis, and glucose transporter translocation. Mol. Cell. Biol. 14:4902-4911.

21. Hausdorff, S.F., et al. 1999. Identification of wortmannin-sensitive targets in 3T3-L1 adipocytes. Dissociation of insulin-stimulated glucose uptake and glut4 translocation. J. Biol. Chem. 274:24677-24684.

22. Semiz, S., et al. 2003. Conventional kinesin KIF5B mediates insulin-stimulated GLUT4 movements on microtubules. EMBO J. 22:2387-2399.

23. Maffucci, T., Brancaccio, A., Piccolo, E., Stein, R.C., and Falasca, M. 2003. Insulin induces phosphatidylinositol-3-phosphate formation through TC10 activation. EMBO J. 22:4178-4189.

24. Jahn, R., and Südhof, T.C. 1999. Membrane fusion and exocytosis. Annu. Rev. Biochem. 68:863-911.

25. Tellam, J.T., McIntosh, S., and James, D.E. 1995. Molecular identification of two novel Munc-18 isoforms expressed in non-neuronal tissues. J. Biol.
Chem. 270:5857-5863.

26. Macaulay, S.L., et al. 2002. Cellular munc18c levels can modulate glucose transport rate and GLUT4 translocation in 3T3L1 cells. FEBS Lett. 528:154-160.

27. Misura, K.M., Scheller, R.H., and Weis, W.I. 2000. Three-dimensional structure of the neuronal-Sec1syntaxin 1a complex. Nature. 404:355-362.

28. Bracher, A., and Weissenhorn, W. 2002. Structural basis for the Golgi membrane recruitment of Sly1p by Sed5p. EMBO J. 21:6114-6124.

29. Reed, G.L., Houng, A.K., and Fitzgerald, M.L. 1999. Human platelets contain SNARE proteins and a Sec1p homologue that interacts with syntaxin 4 and is phosphorylated after thrombin activation: implications for platelet secretion. Blood. 93:2617-2626.

30. Houng, A., Polgar, J., and Reed, G.L. 2003. Munc18syntaxin complexes and exocytosis in human platelets. J. Biol. Chem. 278:19627-19633.

31. Gaisano, H.Y., et al. 2001. Supramaximal cholecystokinin displaces Munc18c from the pancreatic acinar basal surface, redirecting apical exocytosis to the basal membrane. J. Clin. Invest. 108:1597-1611. doi:10.1172/JCI200109110.

32. Voets, T., et al. 2001. Munc18-1 promotes large dense-core vesicle docking. Neuron. 31:581-591.

33. Bryant, N.J., and James, D.E. 2001. Vps45p stabilizes the syntaxin homologue $\operatorname{Tlg} 2 \mathrm{p}$ and positively regulates SNARE complex formation. EMBO J. 20:3380-3388.

34. Yang, C., et al. 2001. Syntaxin 4 heterozygous knockout mice develop muscle insulin resistance. J. Clin. Invest. 107:1311-1318.

35. Schlaepfer, I.R., et al. 2003. Increased expression of the SNARE accessory protein Munc18c in lipid-mediated insulin resistance. J. Lipid Res. 44:1174-1181.

36. Simpson, I.A., et al. 1983. Insulin-stimulated translocation of glucose transporters in the isolated rat adipose cells: characterization of subcellular fractions. Biochem. Biophys. Acta. 763:393-407. 